\title{
LAS CRISIS BANCARIAS. LOS PROBLEMAS JURIDICOS QUE PRODUCEN Y LAS SOLUCIONES DEL ORDENAMIENTO JURIDICO
}

\author{
FELIX MATEO MATEO
}

1. Estructura del trabajo: Se divide en cuatro partes y conclusiones.

2. En la primera parte, se examinan, además de las cuestiones introductorias, los antecedentes de la banca organizada, tanto privada como pública, los perfiles del sistema bancario modemo, su evolución y estado actual, los episodios de crisis bancarias, producidas en la historia financiera, con referencia especial al período más reciente, en el que la mitad de los bancos existentes en España, han visto comprometida su liquidez o solvencia, a finales de los años setenta. Se presta atención a la formación de la banca, dando noticia de los sistemas modemos comparados.

En el plano normativo son analizados los preceptos que regulan las crisis empresariales y especialmente, las reglas existentes sobre la quiebra de las sociedades mercantiles. Los bancos como sociedades mercantiles especiales cobran relevancia al hablar de la crisis, o al tratar la cuestión de las normas sobre suspensión de pagos o quiebra, destacando el escaso valor práctico de los procedimientos del ordenamiento jurídico español sobre quiebras, aplicados a la quiebra de un banco.

En esta parte, también se examinan los ordenamientos jurídicos comparados, especialmente de Alemania, Inglaterra, Italia, Francia y Estados Unidos, que son significativos de las soluciones dadas a las crisis bancarias, así como las Directivas del ordenamiento comunitario sobre la banca y entidades de crédito, dada la incidencia de las mismas sobre el ordenamiento español.

3. La segunda parte comprende el examen de los problemas jurídicos que plantean las crisis bancarias, en relación con los intereses de los depositantes, los acreedores, los accionistas, los trabajadores y el interés general del sistema financiero. En la misma se resalta el carácter primordial de los intereses afectados por la crisis; siendo a este propósito obligado destacar la relevancia del fenómeno en los intereses de los depositantes y de los accionistas o inversores.

4. La tercera parte comprende el examen de las medidas adoptadas desde la perspectiva jurídica, a veces medidas provisionales, tanto de carácter preventivo como corrector, en el ordenamiento jurídico español, como la creación del Fondo de Garantía de Depósitos y el reforzamiento de las funciones del Banco de España en relación con la banca privada, y en el ordenamiento comparado, destacando los instrumentos creados al efecto en los ordenamientos de Alemania, Italia, Francia, Inglaterra, así como las formas de corregir los problemas que produce la crisis de los bancos en el ordenamiento norteamericano. 
5. En la cuarta parte se hace una recapitulación del estado de la cuestión, incidiendo en la necesidad de reforma del Ordenamiento Jurídico; se postula la necesidad de un ordenamiento regulador del sector bancario, debido a que las medidas dictadas hasta el momento, han sido insuficientes, y dado que la especificidad de la actividad bancaria, hace obligada la intervención de las autoridades monetarias, es necesario regular nuevas normas sobre inspección y control de la actividad bancaria, y dictar normas sobre las responsabilidades por su ejercicio. En último término se hace una reflexión sobre la actividad bancaria y sus crisis, así como sus perspectivas futuras, y soluciones para evitar y prevenir las crisis de los bancos, en atención a la concentración bancaria, entidades más competitivas y de tamaño adecuado con vistas al mercado interior.

6. Por último, se elaboran unas conclusiones, que se dirigen a las siguientes cuestiones:

a) Insuficiencia de las medidas adoptadas hasta el momento por el legislador bancario, sobre todo, en relación con las disposiciones dictadas para tutelar intereses afectados o instrumentos jurídicos adoptados, insuficientes e incapaces para resolver de manera satisfactoria problemas de tutela efectiva de los derechos concernientes. Así, es necesario regular responsabilidades no solo contractuales como empresa, sino responsabilidades derivadas de actividades específicas como empresa bancaria y extracontractuales.

b) Se hace precisa una nueva ordenación sistemática de la actividad bancaria, para evitar la elaboración de disposiciones conyunturales con motivo de dificultades o crisis bancarias.

c) Especial regulación de estas empresas a fin de tutelar los intereses del accionista y del inversor, creación de instituciones de protección del inversor, con establecimiento de normas que regulen sistemas de responsabilidad específica, en atención a la especial actividad, se definan sanciones administrativas e incluso penales, para los infractores que actúen con abuso o fraude a los inversores, accionistas y depositantes.

d) Clarificación de normas sobre solvencia y garantía de bancos, a fin de prevenir situaciones de crisis, hacer frente a la excesiva concentración de riesgos que pongan en peligro el sistema financiero, propugnando la objetivación del derecho paraconcursal bancario.

e) Necesidad de reforma en profundidad de la legislación sobre crisis empresariales y en especial del derecho concursal bancario, dentro del esquema y marco de la reforma general emprendida en el derecho mercantil español. 